\title{
Factors associated with women's exposure to mass media for Health Care Information in Ethiopia. A case-control study
}

\author{
Kassahun Dessie Gashu a , Ayenew Engida Yismaw ${ }^{\mathrm{b}}$, Dereje Nibret Gessesse ${ }^{\mathrm{b}, *}$, \\ Yazachew Engida Yismaw ${ }^{\mathrm{c}}$ \\ ${ }^{a}$ Department of Health Informatics, Institute of Public Health, College of Medicine and Health Sciences, University of Gondar, Gondar, Ethiopia \\ ${ }^{\mathrm{b}}$ School of Midwifery, College of Medicine and Health Sciences, University of Gondar, Gondar, Ethiopia \\ ${ }^{\mathrm{c}}$ Department of Pharmacology, School of Health Science, College of Medicine and Health Sciences, Bahr Dar University, Bahr Dar, Ethiopia
}

\section{A R T I C L E I N F O}

\section{Keywords:}

Ethiopia

Mass media

Women's exposure

\begin{abstract}
A B S T R A C T
Introduction: Mass media are often essential to communicate health messages. Women's exposure to mass media remained low in Ethiopia. Evidence was scarce on underlined factors for enhancing women's exposure to mass media.

Objective: This study aimed to assess factors associated with women's exposure to mass media in Ethiopia. Methods: The study was a secondary data analysis of the Ethiopian demographic and health survey 2016. A casecontrol study applied with frequency matching by place of residence and women's educational levels using a 1:1 ratio. A total of 9885 participants (4824 cases and 5061 controls) were involved in the study. Cases were women who had exposure and controls were who did not have exposure to mass media. Women's exposure to mass media is defined as the total number of women aged 15-49 who report exposure to either radio, television, newspapers, or magazines at least once a week. Logistic regressions analysis was conducted and the level of statistical significance was determined by a p-value of less than 0.05 to identify factors associated with women's exposure to mass media.

Result: Being in Women's age group 30-34 years (AOR $=1.19,95 \%$ C.I:1.04-1.35), having own mobile phones $(\mathrm{AOR}=1.92,95 \%$ C.I:1.71-2.15), women ever used internet (AOR $=1.56,95 \%$ C.I:1.13-2.13), Women in the female-headed household (AOR $=0.76,95 \%$ C.I:0.68-0.86), Women in middle (AOR $=1.48,95 \%$ C.I:1.25-1.76), richer $(A O R=2.13,95 \%$ C.I:1.82-2.49) and richest (AOR $=2.67,95 \%$ C.I:2.22-3.21) wealth index, and women visited by health care provider (AOR $=1.41,95 \%$ C.I:1.17-1.71) were factors affecting women's exposure to mass media.

Conclusion: Women's access to mobile phones, internet, and care provider counseling were facilitating factors for exposure to mass media. Younger age women, lower wealth quantile, and female headship in the household were risk factors for the non-exposure of women to mass media. Empowering household wealth and improving access to ICT could improve women's exposure to mass media.
\end{abstract}

\section{Introduction}

Globally, routine use of existing Mass media, such as Television (TV), Radio, and Newspapers is widely used to communicate large populations to messages. Mass media plays a pivotal role in creating health awareness and the adoption of healthy lifestyles. Exposure to mass media offers a change of awareness, knowledge, attitudes, social norms, and behaviors that may lead to positive public health outcomes.
Exposure to general media programming has a strong impact on women's reproductive attitudes and behaviors. ${ }^{2}$ Exposure to mass media can be seen as one of the tools for women empowerment and a powerful predictor of attitude, belief, and action, and education.

Evidence showed that women's exposure to mass media improves maternal and family health. ${ }^{3}$ Women's exposure to mass media messages was also associated with increased contraceptive use and intention to use. ${ }^{4,5}$ Women who read newspapers at least once a week enhanced their birth preparedness and skilled birth attendance. ${ }^{6}$ Exposure to mass

\footnotetext{
* Corresponding author. Tel.: +251962939424.

E-mail addresses: kassahundessie@gmail.com (K.D. Gashu), ayenewe07@gmail.com (A.E. Yismaw), dnibret62@gmail.com (D.N. Gessesse), yachewable@gmail. com (Y.E. Yismaw).
} 


\section{List of abbreviations}

CSA Central Statistical Agency

EDHS Ethiopian Demographic Health Survey

ICT Information Communication Technology

TV Television

ITN Insecticide-treated bed net

media only had $51 \%$ effects on exclusive breastfeeding as well as on related psychosocial factors. ${ }^{7}$

Exposure to a combined index of television, radio, and newspaper was reported as a strong predictor of women's knowledge towards HIV/ AIDS. ${ }^{8}$ Higher levels of exposure to radio is associated with HIV testing among women. ${ }^{9}$ Young women with increased knowledge regarding HIV/AIDS and frequent exposure to mass media (television and radio) had a lesser tendency to stigmatize. ${ }^{10}$ Frequent and continuous AIDS messages on TV can have a positive influence on AIDS knowledge. ${ }^{11}$ Mass media can also play an immense role in improving ITN utilization among women in Sub-Saharan Africa. ${ }^{12}$ Women's exposure to either TV or radio at least once a week showed more likely to enroll in the National Health Insurance Scheme. ${ }^{13}$

In Ethiopian Demographic and Health Survey (EDHS) 2016, the level of exposure to mass media was reported as low. About $74 \%$ of women and $62 \%$ of men had no access to any of the three media (TV, radio, and newspaper) at least once a week. Radio was the most frequently accessed among both women and men ( $17 \%$ and $29 \%$, respectively), followed by television ( $16 \%$ and $21 \%$, respectively). Because of the low literacy rate, print media are not popular among either women (4\%) or men (9\%). Use of the Internet was also an essential tool for access to information. An overall, $4 \%$ of women and $12 \%$ of men age $15-49$ have used the Internet in the last 12 months of $2016 .{ }^{14}$

In the current evidence, women, in particular, have the lowest exposure to mass media in Ethiopia with an unknown factor of disparity. This study aimed to assess factors associated with exposure to mass media among adult women in Ethiopia.

\section{Methods}

\subsection{Study area}

Ethiopia is among the highest populated country in Africa with 2018 estimated 107.53 million people and $50.7 \%$ of the population is females. ${ }^{15}$ Administratively, Ethiopia is divided into nine geographical regions and two administrative cities. The 2016 Ethiopia Demographic and Health Survey (EDHS) is the fourth survey implemented by the Central Statistical Agency (CSA).

Currently, there are about 50 community radio stations, 14 governmental/public and12 private radio broadcasting corporations; and 10 Governmental/public, 16 private TV broadcasting corporations; as well as 15 newspapers and 6 magazines in Ethiopia. ${ }^{16}$

\subsection{Study design}

The data was first collected by a cross-sectional study design using Ethiopian Demography and Health Surveys (EDHS) 2016. A frequency matched case-control study was applied for this study to determine factors associated with Women's Exposure to Mass Media for Health Care Information in Ethiopia. Place of residence (urban or rural) and women's educational levels were variables used for matching cases with the controls using a 1:1 ratio. Cases were women who had exposure to mass media at least once a week and controls were those who did not have at least once a week.

\subsection{Study population, sample size, and sampling technique}

The source population was all women aged 15 to 49 in Ethiopia. Whereas, in the selected enumeration regions, the sample population was all women aged 15-49. The research included all women aged 15-49 who were ordinary members of the selected households, and those who spent the night before the survey in the selected households.

A total of 9885 participants (4824 cases and 5061 controls) were involved in the study. The response rate was $97.8 \%$. Using 2-stage stratified cluster sampling, the 2016 EDHS samples were picked. The detailed methodologies of the survey can be found elsewhere. ${ }^{14}$

\subsection{Study variables}

In the study, the response variable was women's exposure to mass media and independent variables were such as socio-demographic/and socio-economic (maternal age, maternal occupation, maternal educational level, residence, wealth index, partner's occupation, partner's educational level, region, religion), and accesses to media infrastructures (owning mobile, television, radio, using internet, access of electricity, interest to use mass media, Land-line telephone access) were included.

\subsection{Data collection and analysis techniques}

Data were drawn from EDHS (2016) collected from January 18, 2016 , to June 27,2016 , based on a nationally representative sample that provides estimates at the national and regional levels and for urban and rural areas. Women's exposure to mass media is defined as the total number of women aged 15-49 who report exposure to either radio, television, newspapers, or magazines at least once a week. ${ }^{17}$ Respondents were asked how often they read a newspaper, listened to the radio, or watched television. Those who responded at least once a week are considered to be regularly exposed to that form of media.

For analysis, weighted data were used. Data analysis was carried out using descriptive statistics to compute variables of exposure for cases and controls. To conduct logistic analysis, Survey sets were performed because the data were large survey data set. Crude odds ratios (OR) and 95\% confidence intervals (CI) were used to evaluate the correlation between the various independent variables like socio-demographic, socio-economic and accesses to media infrastructures and women's exposure to mass media. Multiple logistic regression analysis was carried out and the adjusted odds ratio was determined after correcting for the effects of the identified confounding variables. The Association of variables was determined at a level of significance p-value less than 0.05. Statistical analyses were performed using STATA version 14 .

\section{Result}

\subsection{Socio-demographic characteristics}

A total of 9885 participants (4824 cases and 5061 controls) were involved in the study. The mean age of the overall participants was 34.76 with $\mathrm{SD} \pm 7.6$ and about $26 \%$ of cases and $27 \%$ of controls were younger aged less than 30 years. Thirty-one percent of the cases and controls were older age women greater than 39 years.

Out of the total participants, $56.8 \%(57.6 \%$ in cases, and $56.1 \%$ of controls) were not educated. Of the total study subjects, $56.9 \%$ (56.9\% in cases and $56.9 \%$ in the control group) were rural residents. Fourteen percent of the study subjects were drawn from Oromia Region. Regarding the partner's education level, $34.8 \%$ (39.3\% of cases and $39.3 \%$ of controls) did not have an education. The wealth index showed that $18.0 \%$ ( $11.2 \%$ of cases and $24.5 \%$ of controls) of respondents were in the poorest wealth index category (Table-1). 
Table 1

Socio-demographic and socio-economic variables of cases and control groups in Ethiopia, EDHS 2016.

\begin{tabular}{|c|c|c|c|}
\hline Variables & Cases, n (\%) & Controls, n (\%) & Total, n (\%) \\
\hline \multicolumn{4}{|l|}{ Mother's Age } \\
\hline$<30$ years & $1231(25.5)$ & $1357(26.8)$ & $2588(26.2)$ \\
\hline 30-34 years & 1055 (21.9) & $980(19.4)$ & $2035(20.6)$ \\
\hline 35-39 Years & $1001(20.8)$ & $1113(22.0)$ & $2114(21.4)$ \\
\hline $40+$ Years & 1537 (31.9) & $1611(31.8)$ & $3148(31.8)$ \\
\hline \multicolumn{4}{|c|}{ Mother's Education level } \\
\hline No education & $2781(57.6)$ & $2838(56.1)$ & $5619(56.8)$ \\
\hline Primary & 1250 (25.9) & $1424(28.1)$ & $2674(27.1)$ \\
\hline Secondary & $519(10.8)$ & $628(12.4)$ & $1147(11.6)$ \\
\hline Higher & $274(5.7)$ & $171(3.4)$ & $444(4.5)$ \\
\hline \multicolumn{4}{|l|}{ Residence } \\
\hline Urban & 2077 (43.1) & $2174(43.1)$ & $4251(43.1)$ \\
\hline Rural & 2747 (56.9) & 2887 (56.9) & 5634 (56.9) \\
\hline \multicolumn{4}{|l|}{ Regions } \\
\hline Tigray & $561(11.6)$ & $536(10.6)$ & $1097(11.1)$ \\
\hline Afar & $434(9.0)$ & $391(7.7)$ & $825(8.3)$ \\
\hline Amhara & $315(6.5)$ & $592(11.7)$ & $907(9.2)$ \\
\hline Oromia & $708(14.7)$ & $698(13.8)$ & $1406(14.2)$ \\
\hline Somali & $417(8.6)$ & $447(8.8)$ & $864(8.7)$ \\
\hline Benishangul-Gumuz & $417(8.6)$ & $564(11.1)$ & $981(9.9)$ \\
\hline SNNPR & $635(13.2)$ & $575(11.4)$ & $1210(12.2)$ \\
\hline Gambela & $365(7.6)$ & $444(8.8)$ & $809(8.2)$ \\
\hline Harari & $498(10.3)$ & $408(8.1)$ & $906(9.2)$ \\
\hline Dire Dawa & $474(9.8)$ & $406(8.0)$ & $880(8.9)$ \\
\hline \multicolumn{4}{|c|}{ Partner's Education level } \\
\hline No education & $1452(30.1)$ & $1991(39.3)$ & $3443(34.8)$ \\
\hline Primary & $1632(33.8)$ & $1305(25.8)$ & $2937(29.7)$ \\
\hline Secondary & $585(12.1)$ & $528(10.4)$ & $1113(11.3)$ \\
\hline Higher & $555(11.5)$ & $424(8.4)$ & $979(9.9)$ \\
\hline \multicolumn{4}{|l|}{ Wealth Index } \\
\hline Poorest & $540(11.2)$ & $1241(24.5)$ & $1781(18.0)$ \\
\hline Poorer & $336(7.0)$ & $679(13.4)$ & $1015(10.3)$ \\
\hline Middle & 468 (9.7) & 635 (12.5) & $1103(11.2)$ \\
\hline Richer & 853 (17.7) & 753 (14.9) & $1606(16.2)$ \\
\hline Richest & $2627(54.5)$ & 1753 (34.6) & $4380(44.3)$ \\
\hline Total & $\begin{array}{l}4824 \\
(100.0)\end{array}$ & $5061(100.0)$ & $9885(100.0)$ \\
\hline
\end{tabular}

\subsection{Access to mass media infrastructures}

Among the total mobile phone owned women, 2306 (61.5\%) has exposure to mass media. On the other 3619 (59.5\%) of women without access to mobile phones did not have exposure to mass media. Among women who ever used internet, 181 (69.6\%) were exposed to mass

Table 2

Access of Media and Related Infrastructure to case and control groups in Ethiopia, EDHS 2016

\begin{tabular}{|c|c|c|c|c|}
\hline Variables & Cases, n (\%) & \multicolumn{2}{|c|}{ Controls, n (\%) } & Total, n (\%) \\
\hline \multicolumn{5}{|c|}{ Own Mobile phone } \\
\hline Yes & $2306(47.8)$ & $1442(28.5)$ & 3748 (37.9) & \\
\hline No & $2518(52.2)$ & 3619 (71.5) & $6137(62.1)$ & \\
\hline \multicolumn{5}{|c|}{ Land-line telephone access ${ }^{a}$} \\
\hline Yes & $309(70.2)$ & $131(29.8)$ & $9354(94.6)$ & \\
\hline No & $4489(48.0)$ & $4865(52.0)$ & $440(4.5)$ & \\
\hline \multicolumn{5}{|c|}{ Access to radio ${ }^{a}$} \\
\hline Yes & $2888(71.8)$ & $1137(28.2)$ & $4025(40.7)$ & \\
\hline No & $1910(33.1)$ & $3859(66.9)$ & $5769(58.4)$ & \\
\hline \multicolumn{5}{|c|}{ Access to $\mathrm{TV}^{\mathrm{a}}$} \\
\hline Yes & $2200(72.5)$ & $836(27.5)$ & $3434(34.7)$ & \\
\hline No & $2598(38.4)$ & $4160(61.6)$ & $6360(64.3)$ & \\
\hline \multicolumn{5}{|c|}{ Ever use of internet } \\
\hline Yes & $181(69.6)$ & $196(30.4)$ & $260(2.6)$ & \\
\hline No & $4643(48.2)$ & $4982(51.8)$ & $9625(97.4)$ & \\
\hline \multicolumn{5}{|c|}{ Access to Electricity $^{a}$} \\
\hline Yes & $2725(56.5)$ & $1872(37.0)$ & $4597(46.5)$ & \\
\hline No & $2073(43.0)$ & $3124(61.7)$ & $5197(52.6)$ & \\
\hline
\end{tabular}

In case $26(0.5 \%)$ and control groups $65(1.3 \%)$, participants were not a dejure resident ${ }^{\mathrm{a}}$ media. A higher proportion of women with access to radio 2888 (71.8\%) and TV 2200 (72.5\%) had exposure to mass media (Table 2).

\subsection{Factors associated with exposure to mass media}

In the binary logistic regression analysis, a bi-variable model shown that variables like women's age, access to a mobile phone, electricity, sex of household, ever use of internet, wealth index, and visited by health care provider were found to be significantly associated with exposure to mass media.

In a multivariable model, factors like; age $30-34$ years, access to a mobile phone, sex of household head, wealth index and to be visited by health care providers were significant predictor variables. Women's age between 30 and 34 years were 1.2 times likely to expose mass media than younger aged women, (AOR $=1.19,95 \%$ C.I: $1.04-1.35$ ). Women who own mobile phones were about 2 times more likely to be exposed to mass media than women without mobile access (AOR $=1.92$, 95\% C.I: $1.71-2.15)$. Women in the female-headed household were a $24 \%$ lower chance to be exposed to mass media (AOR $=0.76,95 \%$ C.I:0.68-0.86). Those women ever used internet were 1.5 times likely to be exposed to mass media (AOR $=1.56,95 \%$ C.I: $1.13-2.13$ ). Women in the middle, richer, and richest wealth index were 1.5, 2.0, and 2.6, respectively higher likely to be exposed and those women having visited by health care providers were 1.4 times higher likely to be exposed to mass media than their counterparts (Table 3 ).

\section{Discussion}

Women's exposure to either TV, radio, or printed media like newspapers or magazines at least once a week determined the minimum exposure level for mass media in order to attain health messages for evidence-based maternal and family health practices. ${ }^{17}$ Hence, knowing enabling factors is a turning point to set policies and strategies for enhancing women's exposure to mass media.

This study pointed out, middle-aged (30-34 years) women were more likely exposed than younger women. Similarly, a study done in

Table 3

Factors associated with women's exposure to mass media in Ethiopia, EDHS 2016.

\begin{tabular}{|c|c|c|c|c|c|}
\hline Variables & \multicolumn{2}{|c|}{ Cases } & Controls & COR $(95 \% \mathrm{CI})$ & AOR $(95 \% \mathrm{CI})$ \\
\hline \multicolumn{6}{|l|}{ Women's Age } \\
\hline$<30$ years & 1231 & 1357 & 1 & & 1 \\
\hline $30-34$ years & 1055 & 980 & 1.19 & $(1.06-1.33)$ & $1.19(1.04-1.35)^{\mathrm{a}}$ \\
\hline $35-39$ years & 1001 & 1113 & .99( & $88-1.11)$ & $.99(.87-1.13)$ \\
\hline $40+$ years & 1537 & 1611 & 1.05 & .95-1.17) & $1.12(.99-1.27)$ \\
\hline \multicolumn{6}{|c|}{ Women own mobile phone } \\
\hline Yes & 2306 & 1442 & 2.30 & $(2.12-2.50)$ & $1.92(1.71-2.15)^{a}$ \\
\hline No & 2518 & 3619 & 1 & & 1 \\
\hline \multicolumn{6}{|c|}{ Access to electricity ${ }^{a}$} \\
\hline Yes & 2725 & 1872 & 2.19 & $(2.02-2.38)$ & $1.03(.90-1.19)$ \\
\hline No & 2073 & 3124 & 1 & & 1 \\
\hline \multicolumn{6}{|c|}{ Sex of household head } \\
\hline Male & 3471 & 3339 & 1 & & 1 \\
\hline Female & 1353 & 1722 & .76 & 69-.82) & $.762(.678-.856)^{a}$ \\
\hline \multicolumn{6}{|c|}{ Ever use of internet } \\
\hline Yes & 181 & 79 & 2.46 & $(1.88-3.21)$ & $1.55(1.13-2.13)^{a}$ \\
\hline No & 4643 & 4982 & 1 & & 1 \\
\hline \multicolumn{6}{|l|}{ Wealth index } \\
\hline Poorest & 540 & 1241 & 1 & & 1 \\
\hline Poorer & 336 & 679 & 1.14 & $.96-1.34)$ & $1.05(.88-1.25)$ \\
\hline Middle & 468 & 635 & 1.69 & $(1.45-1.98)$ & $1.48(1.25-1.76)^{a}$ \\
\hline Richer & 853 & 753 & 2.60 & $(2.26-2.99)$ & $2.13(1.82-2.49)^{a}$ \\
\hline Richest & 2627 & 1753 & 3.44 & $(3.06-3.87)$ & $2.67(2.22-3.21)^{a}$ \\
\hline \multicolumn{6}{|c|}{ Visited by health care workers in last 12 months } \\
\hline Yes & 1854 & 1555 & 1.41 & $(1.30-1.53)$ & $1.41(1.17-1.71)^{\mathrm{a}}$ \\
\hline No & 2970 & 3506 & 1 & & 1 \\
\hline
\end{tabular}

${ }^{a}$ Statistically significant (P-value $\left.<0.05\right)$. In case $26(0.5 \%)$ and control groups 65 (1.3\%), participants were not a dejure resident. 
West Africa on exposure to contraceptive messages, a smaller proportion of adolescent women reported exposure compared to older age groups. ${ }^{18}$ The possible reason could be economical, intellectual improvements ahead of women's age that will enable them to access media and get matured to attend messages.

Women who have access to a mobile phone were about 2 times more likely to have mass media exposure. In EDHS, 2016, women's exposure to family planning messages using new technologies, such as mobile phones (3\%) and the internet (2\%), is limited. ${ }^{14}$ Although internet access and use are still low, it was found to be a prominent predictor of mass media exposure. This could be the intrinsic power of mobile phone and internet technology that creates an information network among people. Mobile cellular penetration in Africa has reached $66 \%$ and is estimated to grow stronger than ever and the same is true in other regions of the world. ${ }^{19}$ In Ethiopia, currently, mobile subscriptions have reached 40 million and aspire to rise to 64 million in the second-growth and transformation plan (GTP-II) period. ${ }^{20}$ This directly or indirectly creates an opportunity that complements audio-visual and printed mass media for health information dissemination in health care.

The household head often determines social, economic, and health phenomena in the occupants. In this study, women in the female-headed household were a $24 \%$ lower chance to have mass media exposure. This may be due to a reduced amount of family wealth index in femaleheaded than male-headed households.

Regarding the wealth index, women in the middle, richer, and richest wealth index were found more likely to have mass media exposure. A higher proportion of women 15-49 who reported mass media exposure were from higher wealth quintiles ${ }^{18}$ that could be associated with had higher education levels and urban residency that allow them more access as compared to lower wealth quantiles.

Women visited by health care workers have shown more likely to have mass media exposure than their counterparts. This could be a provider's counseling and motivation initiated women to commit to attending either of the available mass media.

\section{Conclusion}

Women's access to mobile phones, internet, and health care provider counseling were facilitating factors for exposure to mass media. Younger age women, lower wealth quantile, and female headship in the household were risk factors for the non-exposure of women to mass media. Empowering household wealth and improving access to ICT could improve women's exposure to mass media.

\section{Authors' contributions}

KDG, AEY, YEY, and DNG contributed to the conception and design of the review. Both authors involved in the analysis, interpretation, and write-up of the article. Both approved the manuscript for publication.

\section{Funding}

The author(s) received no specific funding for this work.

\section{Availability of data and materials}

The dataset was analyzed during the current study available from the corresponding author on a reasonable request.

\section{Ethics approval and consent to participate}

An authorization letter for data access was obtained from the DHS program. The 2016 EDHS protocol was reviewed and approved by the national ethics review committee of the Federal Democratic Republic of Ethiopia, Ministry of Science and Technology, and the institutional review board of ICF International. Written informed consent was obtained from all women who participated in the EDHS.

\section{Consent for publication}

Not applicable.

\section{Declaration of competing interest}

Author of this manuscript declared that there is no conflict of interest.

\section{Acknowledgment}

We acknowledge the DHS Program, ICF International for their online provision of the Ethiopian DHS data set.

\section{References}

1 Westoff CF, Akinrinola B. Mass Media and Reproductive Behavior in Africa. DHS Analytical Reports No. 2. Calverton, Maryland: Macro International Inc; 1997.

2 Bankole A, Rodriguez G, Westoff CF. Mass media messages and reproductive behaviour in Nigeria. J Biosoc Sci. 1996;28(2):227-239.

3 Zamawe COF, Banda M, Dube AN. The impact of a community driven mass media campaign on the utilisation of maternal health care services in rural Malawi. BMC Pregnancy Childbirth. 2016;16:21.

4 Islam MM, Hasan AH. Mass media exposure and its impact on family planning in Bangladesh. J Biosoc Sci. 2000;32(4):513-526.

5 Islam MR, Islam MA, Banowary B. Determinants of exposure to mass media family planning messages among indigenous people in Bangladesh: a study on the Garo. J Biosoc Sci. 2009;41(2):221-229.

6 Asp G, et al. Associations between mass media exposure and birth preparedness among women in southwestern Uganda: a community-based survey. Glob Health Action. 2014;7:22904.

7 Nguyen PH, et al. Exposure to mass media and interpersonal counseling has additive effects on exclusive breastfeeding and its psychosocial determinants among Vietnamese mothers. Matern Child Nutr. 2016;12(4):713-725.

8 Jesmin SS, Chaudhuri S, Abdullah S. Educating women for HIV prevention: does exposure to mass media make them more knowledgeable? Health Care Women Int. 2013;34(3-4):303-331.

9 Sano Y, et al. Exploring the linkage between exposure to mass media and HIV testing among married women and men in Ghana. AIDS Care. 2016;28(6):684-688.

10 Asamoah CK, Asamoah BO, Agardh A. A generation at risk: a cross-sectional study on HIV/AIDS knowledge, exposure to mass media, and stigmatizing behaviors among young women aged 15-24 years in Ghana. Glob Health Action. 2017;10(1):1331538.

11 Chatterjee N. AIDS-related information exposure in the mass media and discussion within social networks among married women in Bombay, India. AIDS Care. 1999;11 (4):443-446.

12 Yaya S, et al. Mass media exposure and its impact on malaria prevention behaviour among adult women in sub-Saharan Africa: results from malaria indicator surveys. Glob Health Res Policy. 2018;3:20.

13 Kansanga MM, et al. Examining the association between exposure to mass media and health insurance enrolment in Ghana. Int J Health Plann Manag. 2018;33(2): e531-e540.

14 Central Statistical Agency, C.S.A.E. CSA and ICF: Addis Ababa, Ethiopia. In: Icf, Ethiopia Demographic and Health Sruvey 2016. 2017.

15 Nation United. World population prospects (2017 revision) - united nations population estimates and projections. http://worldpopulationreview.com/countrie s/ethiopia-population/. Accessed September 12, 2018.

16 Corporation EBc. List of mass media in Ethiopia. http://www.eba.gov.et/index.php/ 2013-11-03-08-41-12/2013-11-03-08-40-27. Accessed September 12, 2018.

17 Measure Evaluation. Percent of women who have weekly exposure to mass media. https://www.measureevaluation.org/prh/rh_indicators/gender/wgse/percent-of-wo men-who-have-weekly-exposure-to-mass.

18 Jacobs J, et al. Mass media exposure and modern contraceptive use among married West African adolescents. Eur J Contracept Reprod Health Care. 2017;22(6):439-449.

19 Deivanayagam CN, et al. Prevalence of acquired MDR-TB and HIV co-infection. Indian J Chest Dis Allied Sci. 2002;44(4):237-242.

20 DeMaio J, Sharma D. Tuberculosis therapy and telemedicine. Expet Opin Pharmacother. 2002;3(9):1283-1288. 